\title{
THE DEVELOPMENT OF THE STATE LABOUR RESERVE SYSTEM IN THE LOWER VOLGA REGION IN POSTWAR PERIOD (1945-1952)
}

\author{
Nadezhda Vasilyevna Kuznetsova \\ Doctor of Sciences (History), Professor, \\ Department of Russian History, \\ Volgograd State University \\ histrus@volsu.ru \\ Prosp. Universitetsky, 100, 400062 Volgograd, Russian Federation
}

\begin{abstract}
Two stages are revealed in the development of state labour reserves. The first period lasted from 1945 to 1948, and the second period - from 1949 to 1952. The distinctions of these two stages were determined. The author analyzes the dynamics of quantity and the structure of institutions in the system of state labour reserves in the Astrakhan, Saratov and Stalingrad regions in postwar years. The social and economical factors that had influence on this system were identified. The characters of principal patterns of SSLR's education institutions is provided, the common lines and singularities, significance changes were denoted. The share of young ones from the childish houses into the industrial, handicraft and railways schools in Low Volga River is exposed. The criteria of entering into the education institutions were determined. The interaction of SSLR with children houses was exhibited. The author highlights the status of stuff basis of SSLR in postwar years: shortage of educational buildings and student's homes, equipment's deficiency in industrial workshops and textbooks. The positive changes in staff-technical guarantee of educational institutions to the end of learning period are opening; their causes were analyzed. The author reveals the alterations in staff structure of SSLR and calculates the number of preparing workmen from factory and plant instruct schools; industrial, handicraft and railways schools for enterprises of the Lower Volga region in the fourth five-year plan. The article marks the significance of SSLR in the solution of economic and social problems in postwar society. The author distinguishes the common and the individual in the development of SSLR in the Lower Volga region and in Russia on whole.

Key words: industrial enterprises, qualified workmen, system of state labour reserves, training schools of factories and plants, handicraft and railway colleges.
\end{abstract}

УДК 94(47+57«1945/1952»):331

Дата поступления статьи: 28.10.2015

ББК 63.3(2)631-3

\section{РАЗВИТИЕ СИСТЕМЫ ГОСУДАРСТВЕННЫХ ТРУДОВЫХ РЕЗЕРВОВ В НИЖНЕМ ПОВОЛЖЬЕ В ПОСЛЕВОЕННЫЕ ГОДЫ (1945-1952)}

\footnotetext{
Надежда Васильевна Кузнецова

Доктор исторических наук, профессор кафедры истории России, Волгоградский государственный университет histrus@volsu.ru просп. Университетский, 100, 400062 г. Волгоград, Российская Федерация

Аннотация. В статье проанализирована динамика численности и состава учебных заведений системы государственных трудовых резервов в Астраханской, Саратовской и Сталинградской областях в послевоенные годы. Выявлены факторы, оказавшие влияние на эту систему, раскрыты основные пути ее структурной перестройки. Показаны методы комплектования школ фабрично-заводского обучения, ремесленных и железнодорожных училищ. Освещены изменения критериев приема в учебные заведения. Показано взаимодействие системы государственных трудовых резервов с детскими домами региона. Отражено состояние
} 
материальной базы СГТР, перемены в ее кадровом составе. Подсчитано количество квалифицированных рабочих, подготовленных для предприятий Нижнего Поволжья в четвертой пятилетке. Отмечено значение СГТР в решении экономических и социальных проблем послевоенного общества. Выявлено общее и особенное в развитии системы трудовых резервов в Нижнем Поволжье и стране в целом.

Ключевые слова: промышленные предприятия, квалифицированные рабочие, система государственных трудовых резервов, школы фабрично-заводского обучения, ремесленные и железнодорожные училища.

Одной из главных трудностей послевоенного восстановления народного хозяйства СССР стал дефицит профессиональных рабочих. Ее преодоление напрямую влияло на темпы возрождения экономики, перевод индустрии на качественно новый уровень. Решение кадровой проблемы, как и в годы войны, было невозможно без использования системы государственных трудовых резервов (далее - СГТР).

В первые послевоенные годы центральные и местные власти сосредоточили внимание на наращивании числа школ фабрично-заводского обучения (далее - ФЗО), ремесленных и железнодорожных училищ (далее - РУ и ЖУ) и увеличении их контингента. В течение 1946-1947 гг. в СССР было открыто 1709 учебных заведений СГТР, в результате чего их общее количество составило 4 197, а численность учащихся 1024 тыс. [13, с. 94].

Ускоренные темпы развития СГТР были характерны и для областей Нижней Волги. К концу 1947 г. число школ ФЗО, РУ и ЖУ в регионе достигло максимального уровня. В Саратовской области, отличавшейся высокоразвитой промышленностью, оно составило 36, в Астраханской, имевшей наименьшую индустриальную базу, -26 . Самый существенный прирост количества профессионально-технических учебных заведений произошел в Сталинградской области: с 24 в 1945 г. до 27 в 1946 г. и 34 в 1947 г., что было на 24 \% больше, чем в 1947 г. При этом контингент учащихся вырос за 1946-1947 гг. в Астраханской области в 1,2, в Саратовской - в 2,1, Сталинградской - в 2,7 раза (подсчитано по: [3, л. 52; 6, л. $52 ; 18$, л. 1]).

Ведущую роль в подготовке высококвалифицированных специалистов в СГТР играли РУ. Все крупные заводы региона имели свои базовые РУ с двухгодичным сроком обучения. Число учеников определялось потребностями производства. К началу 1947 г. в РУ Сталинградского тракторного завода обуча- лось 300 , Сталэнергокомбината - 400 человек и т. д. [14, л. 1].

Наряду с РУ промышленные предприятия применяли краткосрочную подготовку рабочих через школы ФЗО, действовавшие по трех-, четырех-, шестимесячным программам. В отличие от РУ школы ФЗО готовили кадры не только для промышленности, но и строительных организаций, сферы бытового обслуживания. Острая потребность в строителях в Сталинграде привела к тому, что к концу 1946 г. из 15 школ ФЗО 7 действовали при строительных трестах («Главсталинградстрой», «Сталинградметаллургстрой», «Тракторострой» и др.). Из 5 новых школ, организованных в 1947 г., 4 имели строительный профиль. В итоге к концу 1948 г. 79,3 \% всех учеников школ ФЗО готовились к работе на стройках города [14, л. $1 ; 15$, л. $39 ; 17$, л. 14].

«Кадровый голод» в первые послевоенные годы обусловил численное преобладание школ ФЗО над РУ. Особенно заметным это было в Сталинграде. По данным на 10 декабря 1946 г. в городе действовали 15 школ ФЗО с общим контингентом 3800 учащихся и 5 РУ, готовивших 1676 молодых рабочих [14, л. 1, 3].

В 1948-1949 гг. возникла необходимость в количественных и качественных изменениях в СГТР. Главными причинами были окончание основных восстановительных работ в экономике, частичная стабилизация производственных коллективов, расширение подготовки непосредственно на заводах. Система профтехобразования ощутила влияние и других важных факторов: структурной перестройки промышленности, освоение предприятиями новой техники и высокопроизводительных технологий.

Основными путями реорганизации СГТР стали закрытие неперспективных и слияние однотипных школ ФЗО, преобразование школ в РУ и организация новых РУ. Итоги проведенной работы отражены в таблице 1. 


\section{Число и типы заведений системы трудовых резервов в областях Нижнего Поволжья в 1952 г.}

\begin{tabular}{|l|c|c|c|}
\hline \multicolumn{1}{|c|}{ Типы учебных заведений } & $\begin{array}{c}\text { Астраханская } \\
\text { область }\end{array}$ & $\begin{array}{c}\text { Саратовская } \\
\text { область }\end{array}$ & $\begin{array}{c}\text { Сталинградская } \\
\text { область }\end{array}$ \\
\hline Ремесленные училища & 6 & 14 & 7 \\
\hline Специальные училища & 2 & 3 & 2 \\
\hline Железнодорожные училища & - & 5 & 12 \\
\hline Школы ФЗО & 4 & 8 & 23 \\
\hline Всего & 12 & 30 & \\
\hline
\end{tabular}

Примечание. Источник: [1, л. 41; 5, л. 36; 6, л. 79; 20, л. 11].

Согласно показателям таблицы 1 , в 1952 г., как и в 1946-1947 гг., наибольшее количество учебных заведений СГТР функционировало в Саратовской области, наименьшее - в Астраханской. Число РУ в этих областях вдвое превысило численность школ ФЗО, в Сталинградской их соотношение стало равным. Наличие сравнительно большого количества школ ФЗО в Сталинградской области было вызвано сохранением потребности в рабочих массовых профессий. В 1952 г. из 11 сталинградских учебных заведений этого типа 8 готовили каменщиков, плотников, сантехников, штукатуров и строителей других специальностей. В то же время три школы ФЗО, обучавшие рабочих для промышленных предприятий, были переведены на десятимесячную программу для повышения квалификации выпускников [20, л. 11, 12].

Структурная перестройка экономики привела к соответствующим изменениям в профиле учебных заведений. В конце 1940-х - начале 1950-х гг. в Нижнем Поволжье расширилась подготовка рабочих для металлургической, машиностроительной и швейной промышленности и сократился выпуск специалистов для деревообрабатывающей и электроэнергетической индустрии, средств связи. В целом же перечень специальностей вырос. Самый широкий выбор профессий предлагали школы ФЗО и РУ Саратовской области, где в 1952 г. их число было доведено до 46 [5, л. 36].

Особенностью реорганизации СГТР в послевоенное время стало создание специальных РУ с учетом не только потребности в кадpax, но и гендерной принадлежности. Эта работа проводилась в рамках эксперимента по раздельному обучению мальчиков и девочек и не получила широкого распространения.
К концу изучаемого периода в Нижнем Поволжье действовало только 7 таких РУ: по 2 в Астраханской и Сталинградской и 3 - в Саратовской области.

Первостепенное значение придавалось не экспериментам, а обеспечению набора учащихся школ ФЗО и РУ. Их общая численность определялась Министерством трудовых резервов в соответствии с установками Совета Министров СССР. Областные управления трудовых резервов (далее - ОУТР) получали общие пятилетние и годовые планы, учитывавшие потребности предприятий и строек в квалифицированной рабочей силе.

В исследуемый период использовались два метода комплектования учебных заведений: призыв и добровольный набор. Первый метод преобладал в 1945-1947 годах. Он о3начал добровольно-принудительное направление подростков в школы ФЗО, РУ и ЖУ согласно разнарядке ОУТР для всех городских и сельских районов. Областные управления допускали перевыполнение планов, создавая резерв на случай отсева учеников, а при их недовыполнении проводили дополнительные наборы. Второй метод стал доминирующим с 1948 г., когда РУ региона полностью, а школы ФЗО частично обеспечили себя учащимися путем свободного приема. Аналогичная ситуация сложилась и в масштабе страны: в 1948 г. 82 \% учеников СГТР поступили в учебные заведения добровольно [13, с. 95]. К 1953 г. не только училища, но и школы ФЗО полностью перешли на свободный прием.

Причиной поворота молодежи в сторону профессионального образования стала не только его доступность (отсутствие вступительных экзаменов, государственное обеспечение). Нацеленное на обучение городским 
профессиям, оно давало реальный шанс легального «раскрестьянивания». Дополнительными стимулами к этому стали голод 19461947 гг., охвативший в основном сельские районы, денежная реформа 1947 г. и другие меры, усилившие разрыв в уровне жизни горожан и сельчан. Не случайно доля деревенских юношей и девушек в системе гострудрезервов составила в 1946-1950 гг. 77,1 \%, в 1952 г. 72,1 \% (подсчитано по: [12, с. 306]).

В 1945-1946 гг. призыв в учебные заведения СГТР осуществлялся независимо от уровня образования подростков. В $1947-$ 1948 гг. обязательным условием зачисления стало наличие общеобразовательной подготовки в объеме 1-7 классов. Но общий уровень знаний учеников остался низким, так как их школьные годы совпали с военными. Лишь каждый четвертый поступивший в школы ФЗО и РУ закончил 4-7, остальные 1-3 класса.

Улучшение технической оснащенности предприятий вызвало потребность повышения общеобразовательной подготовки учащихся. В конце четвертой пятилетки школам ФЗО и училищам было запрещено принимать учеников, не прошедших четырехклассное обучение. Это положительно сказалось и на других показателях. Если в 1945/1946 учебном году лишь 9 \% поступивших в РУ и ЖУ Саратовской области имели неполное среднее образование (7 классов), то в 1950/1951 - $45 \%$, а в Сталинградской $-52,7$ \% [21, с. 62].

Учебные заведения СГТР стали обращать внимание и на возрастные особенности учеников. В 1950-1952 гг. в РУ и ЖУ региона, готовившие рабочих престижных профессий (электросварщиков, электромонтеров, помощников машинистов и др.), как правило, зачислялись подростки 14-15 лет. В те же училища могли поступить лица 16-17 лет, но при наличии семиклассного образования. Эти правила не соблюдались при формировании групп по менее популярным специальностям (котельщиков, кузнецов, формовщиков и др.). Единственным критерием при этом являлось начальное образование.

Преобладающее большинство учащихся СГТР в регионе составили лица мужского пола, что определялось специализацией школ ФЗО и РУ, обусловленной структурой народ- ного хозяйства и приоритетами в его развитии. Кроме того, многие школы и училища не принимали на обучение девушек из-за невозможности их отдельного от юношей размещения в общежитиях.

Особенностью послевоенного состава учащихся гострудрезервов был значительный удельный вес детдомовских детей. Вопрос об использовании СГТР в их социальной адаптации приобрел особую актуальность в условиях голода 1946-1947 годов. Наиболее остро он стоял в Сталинграде в связи с большой перегруженностью детприемника и детских домов области.

30 июля 1947 г. председатель Сталинградского горсовета Д.М. Пигалев провел совещание с участием членов горкома ВКП (б), заведующего гороно, заместителя начальника ОУТР, начальника детприемника и других ответственных работников. Было принято решение, обязавшее облуправление трудовых резервов зачислить 300 мальчиков в специальное мужское РУ-3 г. Камышина, 100 девочек в специальное женское РУ-2 г. Сталинграда. В результате этого освободились места в детдомах и детприемнике для беспризорных и безнадзорных детей, нуждавшихся в устройстве $[16$, л. 30$]$. В целом, по данным облоно, за 1944-1950 гг. через учебные заведения СГТР прошло 800 выпускников детских домов, что составило $55 \%$ от их общего количества (подсчитано по: [19, л. 31]).

Детдомовцы были значительной, но не преобладающей частью учащихся школ ФЗО и училищ. В 1952 г. их доля среди принятых в РУ Сталинградской области достигла $38 \%$. Аналогичный показатель по школам ФЗО и училищам Астраханской области за тот же год был равен 28,8 \% (подсчитано по: [ 1, л. 23; 6 , л. 79]. Исключение составили специальные РУ Астраханской и Сталинградской областей. Сталинградское ОУТР направляло в них в основном воспитанников детдомов, причем в РУ-3 преимущественно детей погибших воинов Красной армии и партизан. Оба спецучилища Астраханской области (и мужское, и женское) укомплектовывались только за счет детских домов и детприемника. В 1952 г. в них находились 317 мальчиков и 253 девочки $[7$, л. $79 ; 19$, л. 34]. Это позволяло учитывать особенности детдомовского контингента в 
процессе профессионального обучения и воспитательной работы.

В 1950 г. Сталинградское ОУТР, анализируя итоги прошлых лет, пришло к выводу, что детдома стремились направить в школы ФЗО и РУ самых трудных подростков, в том числе в возрасте до 14 лет, не имевших начального образования, что негативно сказывалось на качестве их обучения. В связи с этим ОУТР приняло ряд мер. Оно закрепило детские дома за определенными училищами; за два месяца до начала приема в РУ просило облоно предоставить списки детдомовцев, намеченных для направления в училища. ОУТР командировало работников РУ в детские дома для отбора подростков. Проверявшие установили, что, как и в предыдущие годы, многие воспитанники, внесенные в списки, были моложе 14 лет, некоторые закончили 3 класса вместо указанных четырех. Итогом устранения недостатков явилось улучшение состава детдомовцев в РУ. Отбор учащихся непосредственно в детских домах стал с 1950 г. важной составной частью работы Сталинградского ОУТР [19, л. 29, 35].

Развитие системы гострудрезервов в послевоенные годы было невозможно без существенного укрепления ее материальной базы. После окончания войны во всех нижневолжских областях стали очевидными несколько проблем. Во-первых, рост числа учащихся требовал расширения площадей учебных корпусов и общежитий. Большинство зданий школ ФЗО, РУ и ЖУ нуждались в капремонте. 16 июня 1946 г. Совет Министров СССР принял постановление «О строительстве и восстановлении ремесленных, железнодорожных училищ и школ ФЗО». В связи с его невыполнением 17 июня 1947 г. Совмин вторично обязал отраслевые министерства возвести необходимые здания [17, л. 83]. Однако до конца 1940-х гг. это не было сделано.

Во-вторых, недостаток оборудования в производственных мастерских и его изношенность препятствовали рациональной организации учебного процесса. Например, в Саратовском РУ № 10 (базовое предприятие один из ведущих заводов региона ГПЗ-3), по данным на 9 июня 1948 г., плановый контингент учащихся составлял 350 человек. РУ располагало достаточно хорошо оснащенны- ми учебными кабинетами, но в производственных мастерских из 30 единиц оборудования работало только 9, что не обеспечивало единовременного обучения даже одной группы [4, л. 130].

Значительная часть станков РУ и школ ФЗО имело устаревшие конструкции, не соответствовавшие заводским. Актуальным оставался и вопрос обеспечения учеников инструментами и материалами. ОУТР и учебные заведения полностью осваивали средства на приобретение современного оборудования и электрифицированного инструмента, но до конца четвертой пятилетки не добились заметного обновления производственной базы.

В-третьих, дополнительные трудности в обучении создавал дефицит учебников.

Наличие всех этих проблем вызывалось ухудшением состояния материальной базы СГТР в военные годы, ограниченностью выделявшихся ей финансовых средств и модернизированного оборудования, приоритетным направлением их непосредственно в производство.

Тем не менее к концу 1940-х гг. усилиями местных органов власти, ОУТР и самих учебных заведений обозначились позитивные сдвиги. Завершилась радиофикация школ ФЗО, РУ и ЖУ. Выросло число аудиторий и специальных кабинетов, увеличились поступления новых станков в производственные мастерские. Было отремонтировано бездействовавшее оборудование. В результате этого все учащиеся были обеспечены постоянными рабочими местами при двухсменном режиме обучения. Необходимым условием освоения теоретических знаний стали заметное пополнение числа учебных пособий, регулярное снабжение школ ФЗО, РУ и ЖУ тетрадями и канцтоварами.

Дополнительные возможности для укрепления материальной базы появились в начале 1950-х гг. в связи с выполнением четвертого пятилетнего плана и переходом промышленности на качественно новый уровень. В 1951-1952 гг. главное внимание уделялось двум моментам: увеличению библиотечных фондов и переоборудованию мастерских. Последнее позволило ввести односменное производственное обучение с предоставлением ученикам индивидуальных мест. В большинстве училищ и школ перешли к работе на модернизированных станках и обо- 
рудовании с применением передовых технологий и эффективных методов организации труда, что способствовало повышению квалификации выпускников школ ФЗО и РУ.

Постепенно с большими трудностями решалась и проблема кадров. Уже в первые послевоенные годы областные управления гострудрезервов почти полностью укомплектовали штат учебных заведений. К концу исследуемого периода выросла численность работников с законченным средним и средним специальным образованием. Увеличилась, хотя и незначительно, доля лиц с высшим образованием. Позитивное значение имела также система мер по распространению педагогических знаний. Типичной приметой времени стал рост партийно-комсомольской прослойки в коллективах. Несмотря на высокую сменяемость кадров, составлявшую до половины работников, местные власти сохранили костяк высококвалифицированных преподавателей. Все это способствовало выживаемости системы гострудрезервов, ее приспособлению к потребностям времени.

В конце 1940-х - начале 1950-х гг. изменилось место и роль СГТР в социально-экономической жизни страны в связи с интенсификацией производства, насыщением многих предприятий кадрами и распространением других, менее затратных форм обучения рабочих. К 1953 г. количество школ ФЗО, РУ и ЖУ в Нижнем Поволжье уменьшилось в 1,5 раза, а численность учащихся - в 1,7 раза по сравнению с 1947 г. (см. табл. 2).

Наибольшее сокращение произошло в Астраханской области, наименьшее - в Саратовской, что напрямую зависело от структуры промышленности, уровня и темпов ее развития. Сужение СГТР в регионе было ме- нее значительным, чем в стране в целом, где количество школ ФЗО, РУ и ЖУ снизилось в 1,9 раз, а учащихся - в 2,1 раза. Эта особенность Нижнего Поволжья вызывалась сохранением сравнительно высоких потребностей в квалифицированной рабочей силе в связи с динамичным развитием индустрии.

В целом можно констатировать значительную роль СГТР в удовлетворении потребностей народного хозяйства в квалифицированных кадрах. Только в четвертой пятилетке (1946-1950 гг.) она подготовила в масштабе страны 3,4 млн работников, что составило одну четвертую часть от всех обученных рабочих. За тот же период школы ФЗО, РУ и ЖУ Нижневолжского региона выпустили 69 тыс. молодых кадров, в том числе 9,3 тыс. в Астраханской, 30,8 тыс. в Саратовской и 28,9 тыс. в Сталинградской областях [8, с. 131; 9 , с. $158 ; 10$, с. $211 ; 11$, с. 220].

Укрепление материальной базы СГТР, оптимизация кадрового состава, улучшение отбора учеников способствовали не только выполнению количественных показателей, но и повышению качества обучения. Начиная с 1949 г. около 70 \% воспитанников школ ФЗО и РУ поступали на предприятия, имея 4-6 разряды.

Таким образом, СГТР сыграла существенную роль в решении экономических проблем послевоенного общества. Не менее важными были и ее социальные функции: приобщение к взрослой трудовой жизни детдомовцев и подростков из малообеспеченных семей, главным образом деревенских. Используя СГТР, страна готовила нужные ей кадры за государственный счет, создав им равные возможности, что ассоциировалось в сознании послевоенного поколения с социальной справедливостью.

Таблииа 2

Число учебных заведений и численность учащихся системы трудовых ресурсов в Нижнем Поволжье в 1947 и 1952 гг. (на конец года)

\begin{tabular}{|l|c|c|c|c|}
\hline \multirow{2}{*}{ Область } & \multicolumn{2}{|c|}{ Учебных заведений СГТР } & \multicolumn{2}{c|}{ Учащихся } \\
\cline { 2 - 5 } & 1947 г. & 1952 г. & 1947 г. & 1952 г. \\
\hline Астраханская & 26 & 12 & 4530 & 2358 \\
\hline Саратовская & 36 & 30 & 11250 & 7368 \\
\hline Сталинградская & 34 & 23 & 8193 & 4063 \\
\hline Нижнее Поволжье & 96 & 65 & 23973 & 13789 \\
\hline СССР & 4197 & 2256 & 1024 тыс. & 484 тыс. \\
\hline
\end{tabular}

Примечание. Источник: [1, л. 41; 3, л. 52; 5, л. 36; 12, с. 303; 13, с. 94; 19, л. 1, 10-14]. 


\section{СПИСОК ЛИТЕРАТУРЫ}

1. Государственный архив Волгоградской области (далее - ГАВО). - Ф. 686. - Оп. 9. - Д. 227.

2. ГАВО. - Ф. 686. - Оп. 19. - Д. 227.

3. Государственный архив новейшей истории Саратовской области (далее - ГАНИСО). - Ф. 594. Оп. 2. - Д. 85.

4. ГАНИСО. -Ф. 594. - ОП. 2. - Д. 814.

5. ГАНИСО. - Ф. 594. - Оп. 2. - Д. 2097.

6. Государственный архив современной документации Астраханской области (далее-ГАСДАО). Ф. 325.-Оп. 4. - Д. 160.

7. ГАСДАО. - Ф. 325. - Оп. 20. - Д. 3.

8. Народное хозяйство Астраханской области : стат. сб. - Саратов : Госстатиздат, Сарат. отдние, $1958 .-160 \mathrm{c}$.

9. Народное хозяйство Саратовской области : стат. сб. - Саратов : Госстатиздат, Сарат. отд-ние, 1959. -205 c.

10. Народное хозяйство Сталинградской области: стат. сб. - Саратов : Госстатиздат, Сарат. отдние, 1957. $-319 \mathrm{c}$.

11. Промышленность и рабочий класс СССР. 1946-1950 : документы и материалы / сост. С.Р. Левина и др., отв. ред. М.И. Хлусов. - М. : Наука, 1989. - 386 с.

12. Труд в СССР : стат. сб. - М. : Статистика, 1968. - 342 с.

13. Хлусов, М. И. Развитие советской индустрии (1946-1958 гг.) / М. И. Хлусов. - М. : Наука, 1977. $-280 \mathrm{c}$.

14. Центр документации новейшей истории Волгоградской области (далее-ЦДНИВО). - Ф. 71. Оп. 6. - Д. 45.

15. ЦДНИВО. - Ф. 71. - Оп. 7. - Д. 37.

16. ЦДНИВО. -Ф. 71. - Оп. 7. - Д. 47.

17. ЦДНИВО. - Ф. 113. - Оп. 25. - Д. 157.

18. ШДНИВО. - Ф. 113. - Оп. 30. - Д. 51.

19. ЦДНИВО. -Ф. 113. - Оп. 35. - Д. 141.

20. ЦДНИВО. -Ф. 113. - Оп. 39. - Д. 424.

21. Широков, Г. А. Промышленные рабочие послевоенного Поволжья. 1945-1960 гг. / Г. А. Широков. - Саратов : Изд-во Сарат. ун-та, 1987. - 141 с.

\section{REFERENCES}

1. Gosudarstvennyy arkhiv Volgogradskoy oblasti [State Archive of the Volgograd region], F. 686, Op. 9, D. 227.

2. Gosudarstvennyy arkhiv Volgogradskoy oblasti [State Archive of the Volgograd region], F. 686, Op. 19, D. 227.

3. Gosudarstvennyy arkhiv noveyshey istorii Saratovskoy oblasti [State Archive of Modern History of the Saratov Region], F. 594, Op. 2, D. 85.
4. Gosudarstvennyy arkhiv noveyshey istorii Saratovskoy oblasti [State Archive of Modern History of the Saratov Region], F. 594, Op. 2, D. 814.

5. Gosudarstvennyy arkhiv noveyshey istorii Saratovskoy oblasti [State Archive of Modern History of the Saratov Region], F. 594, Op. 2, D. 2097.

6. Gosudarstvennyy arkhiv noveyshey dokumentatsii Astrakhanskoy oblasti [State Archive of Modern Documentation of the Astrakhan Region], F. 325, Op. 4, D. 160.

7. Gosudarstvennyy arkhiv noveyshey dokumentatsii Astrakhanskoy oblasti [State Archive of Modern Documentation of the Astrakhan Region], F. 325 , Op. 20, D. 3.

8. Narodnoe khozyaystvo Astrakhanskoy oblasti: stat. $s b$ [National Economy of the Astrakhan Region: Statistical Collection]. Saratov, Gosstatizdat Publ., 1958. 160 p.

9. Narodnoe khozyaystvo Astrakhanskoy oblasti: stat. $s b$ [National Economy of the Astrakhan Region: Statistical Collection]. Saratov, Gosstatizdat Publ., 1959. 205 p.

10. Narodnoe khozyaystvo Astrakhanskoy oblasti: stat. $s b$ [National Economy of the Astrakhan Region: Statistical Collection]. Saratov, Gosstatizdat Publ., 1957. 319 p.

11. Levina S.R., Khlusov M.I. Promyshlennost $i$ rabochiy klass SSSR. 1946-1950: dokumenty $i$ materialy [Industry and the Working Class of the USSR. 1946-1950: Documents and Materials]. Moscow, Nauka Publ., 1989. 386 p.

12. Trud v SSSR: stat. sb. [Labour in the USSR: Statistical Collection]. Moscow, Statistika Publ., 1968.342 p.

13. Khlusov M.I. Razvitie sovetskoy industrii (1946-1958 gg.) [The Development of Soviet Industry]. Moscow, Nauka Publ., 1977. 280 p.

14. Tsentr dokumentatsii noveyshey istorii Volgogradskoy oblasti [The Centre of Documentation of Modern History of the Volgograd Region], F. 71, Op. 6, D. 45.

15. Tsentr dokumentatsii noveyshey istorii Volgogradskoy oblasti [The Centre of Documentation of Modern History of the Volgograd Region], F. 71, Op. 7, D. 37.

16. Tsentr dokumentatsii noveyshey istorii Volgogradskoy oblasti [The Centre of Documentation of Modern History of the Volgograd Region], F. 71, Op. 7, D. 47.

17. Tsentr dokumentatsii noveyshey istorii Volgogradskoy oblasti [The Centre of Documentation of Modern History of the Volgograd Region], F. 113, Op. 25, D. 157.

18. Tsentr dokumentatsii noveyshey istorii Volgogradskoy oblasti [The Centre of Documentation of Modern History of the Volgograd Region], F. 113, Op. 30, D. 51. 
19. Tsentr dokumentatsii noveyshey istorii Volgogradskoy oblasti [The Centre of Documentation of Modern History of the Volgograd Region], F. 113, Op. 35, D. 141.

20. Tsentr dokumentatsii noveyshey istorii Volgogradskoy oblasti [The Centre of Documentation of Modern History of the Volgograd Region], F. 113, Op. 39, D. 424.

21. Shirokov G.A. Promyshlennye rabochie poslevoennogo Povolzhya. 1945-1960 gg. [Industrial Workers of Post-War Volga Region. 1945-1960]. Sapatov, Izd-vo Sapatovskogo un-ta, 1987. 141 p. 